\title{
A afeição dos cidadãos pelos políticos mal-afamados: identificando os perfis associados à aceitação do "rouba, mas faz" no Brasil
}

\author{
\begin{tabular}{c}
\hline \hline Robert Bonifácio \\
$\begin{array}{c}\text { Doutorando e Professor Substituto do Programa } \\
\text { de Pós-Graduação em Ciência Política } \\
\text { Universidade Federal de Minas Gerais }\end{array}$ \\
\hline \hline
\end{tabular}
}

Resumo: O artigo investiga os perfis de cidadãos associados favoravelmente à ideia do "rouba, mas faz", que significa concordância com a conduta de políticos que incorrem em atos de corrupção, mas que realizam um governo entendido como satisfatório. Utiliza-se como material empírico dois surveys de abrangência nacional, realizados em 2002 e 2006, e os principais resultados obtidos com as análises dos dados apontam para o forte rechaçamento da ideia de "rouba, mas faz" e para a importância explicativa de variáveis que indicam avaliação e desconfiança institucional.

Palavras-chave: "rouba, mas faz"; avaliação institucional; confiança institucional; corrupção

Abstract: The paper analyses the citizen's profiles positively associated with the idea of "he steals, but get things done" that means agreement with the conduct of politicians who incur acts of corruption, but that performs a government perceived as satisfactory. It is used as empirical data two nationwide surveys, conducted in 2002 and 2006, and the main results of data's analysis are the strong rejection of "he steals, but get things done" idea and distrust of representative actors and institutions.

Keywords: "he steals, but get things done"; institutional evaluations; institutional trust; corruption 
BONIFÁCIO, R. A afeição dos cidadãos pelos políticos mal-afamados: identificando...

\section{Introdução ${ }^{1}$}

Com o advento de novas democracias durante o período que ficou conhecido como a "terceira onda de democratização", de 1975 a meados da década de 1990 (HUNTINGTON, 1994), boa parte dos interesses dos especialistas migrou dos determinantes da emergência de democracias para as discussões sobre a qualidade desses novos regimes (DIAMOND; MORLINO, 2004, 2005). Entre os temas envolvidos nessa questão, a corrupção aparece com destaque, uma vez que o primado da lei (rule of law) e a accountability horizontal e vertical são entendidos como precondições essenciais para a existência de uma democracia de qualidade.

Sabe-se que a corrupção é um fenômeno global com incidência variada, sendo sua prática geralmente mais difundida e mais sistematicamente enraizada nos países subdesenvolvidos (ou em desenvolvimento) do que nos países desenvolvidos, conforme indicam os resultados de pesquisas comparativas realizadas por Klitgaard (1988). É natural que a amplitude do fenômeno o ponha em evidência entre os acadêmicos e que muitos estudos a respeito, em diversas áreas do conhecimento, sejam produzidos.

No campo da Ciência Econômica, as pesquisas são abundantes e, de modo geral, indicam que a corrupção gera efeitos nocivos para a economia dos países, uma vez que aumenta os custos das transações financeiras, reduz os investimentos externos e atravanca o crescimento econômico (MAURO, 1995; AIDT, 2003; SHLEIFER; VISHNY, 2003).

Já no campo da Ciência Política, as considerações a respeito nunca foram consensuais, afirma Seligson (2002). De acordo com ele, autores como Key (1949), Merton (1957), Huntington (1968), Waterbury (1976) e Leys (1989) entendem que as práticas corruptas podem ser benéficas para o sistema político por funcionarem como instrumento que desata os nós da burocracia estatal, em especial nos países subdesenvolvidos e/ou ditatoriais. Por outro lado, há autores que procuram evidenciar os aspectos negativos que a corrupção provoca aos cidadãos e aos sistemas políticos. Doig e Mclvor (1999), por exemplo, encontram uma associação entre altas taxas de percepção de corrupção e baixos níveis de confiança institucional. Já Seligson (2002) vê relação entre experiências com atos de corrupção com baixo apoio ao regime democrático e baixo patamar de confiança interpessoal. Della Porta (2000), por sua vez, considera que a corrupção é causa e efeito de desempenhos governamentais pífios.

Este artigo focaliza a corrupção, mas em uma forma ainda pouco estudada pelos especialistas. O objeto de análise são os posicionamentos individuais favoráveis ao "rouba, mas faz", isto é, as considerações positivas sobre políticos que são vistos como bons governantes, apesar de possuírem a pecha de corruptos. O principal objetivo da investigação é identificar os perfis sociais associados à aceitação do "rouba, mas faz" no Brasil. Para tanto, são apresentadas as contribuições da literatura

\footnotetext{
${ }^{1}$ Agradeço à minha orientadora, Dr. ${ }^{a}$ Mônica Mata Machado de Castro, e aos amigos, Me. Frederico Batista Pereira e Dr. Jorge Alexandre Neves, pelas valiosas críticas ao longo do processo de construção do artigo. Também agradeço ao CESOP/ Unicamp, em especial à Dr. ${ }^{a}$ Rachel Meneguello, por ter me cedido gratuitamente os resultados das duas pesquisas de opinião aqui utilizadas.

2 O CSES-ESEB 2002 foi fruto da parceria entre CESOP (Centro de Estudos em Opinião Pública da Universidade Estadual de Campinas) e DataUff (Núcleo de Pesquisas, Informações e Polß̊飞łąs Públicas da Universidade Federal Fluminense) e contou com
} 
OPINIÃO PÚBLICA, Campinas, vol. 19, n², novembro, 2013, p. 320-345

especializada e realizados testes empíricos com dados dos seguintes surveys: o "Estudo Eleitoral Brasileiro" (ESEB), de 2002², e "A Desconfiança dos Cidadãos das Instituições Democráticas", de $2006^{3}$.

Após esta introdução, faz-se uma definição sobre o "rouba, mas faz" e descrevem-se os dados relacionados. Em sequência, discute-se a contribuição da literatura especializada e formulam-se hipóteses sobre os perfis sociais associados. Segue-se a isso a análise empírica do problema, através da utilização de testes estatísticos que indicam respostas às principais indagações. Por fim, são feitas as considerações finais.

\section{“Rouba, mas faz”: definição e aproximação empírica}

Há alguns anos, foi cunhado pela imprensa nacional o termo "rouba, mas faz" para designar políticos que gozam de popularidade por serem vistos como fazedores de obras ou por realizarem bons governos, mas que possuem a pecha de corruptos. Relacionou-se o termo primeiramente a Adhemar de Barros. Em período recente, coube a Paulo Maluf tal reputação, apesar do termo poder ser aplicado a muitos outros políticos do país 4 .

Não se pretende investigar opiniões referentes a qualquer político em específico. As variáveis utilizadas sequer mencionam nomes, sendo constituídas de frases que aludem à ideia do "rouba, mas faz". As variáveis indicadoras de cada uma das duas pesquisas utilizadas encontram-se no Quadro 1:

Quadro 1

Variáveis indicadoras do "rouba, mas faz"

\section{ESEB 2002}

Para cada uma das frases que eu falar, gostaria que o (a) senhor (a) dissesse se concorda muito, concorda um pouco, discorda um pouco ou discorda muito.

1. Não faz diferença se um político rouba ou não, o importante é que ele faça as coisas que a população precisa; 2. É melhor um político que faça muitas obras, mesmo que roube um pouco, do que um político que faça poucas obras e não roube nada;

3. Um político que faz muito e que rouba um pouco merece o voto da população;

4. Um político que faz um bom governo deve poder desviar dinheiro público para financiar sua campanha

\section{DESCONFIANCCA 2006}

Vou ler algumas frases sobre os políticos e gostaria de saber se você concorda muito, concorda pouco, discorda muito ou discorda pouco de cada uma delas:

1. Não faz diferença se um político rouba ou não, o importante é que ele faça as coisas que a população precisa;

2. Um político que faz muito e que rouba um pouco merece o voto da população;

3. Um político que faz muito e que rouba um pouco não merece ser condenado pela justiça;

4. Um político que faz um bom governo deve poder desviar dinheiro público para financiar sua campanha eleitoral; 5. O melhor político é o que faz muitas obras e realizações, mesmo que roube um pouco.

Fonte: "Estudo Eleitoral Brasileiro" (2002) e "A Desconfiança dos Cidadãos das Instituições Democráticas" (2006).

2 O CSES-ESEB 2002 foi fruto da parceria entre CESOP (Centro de Estudos em Opinião Pública da Universidade Estadual de Campinas) e DataUff (Núcleo de Pesquisas, Informações e Políticas Públicas da Universidade Federal Fluminense) e contou com o financiamento da CAPES (Coordenação de Aperfeiçoamento de Pessoal de Nível Superior). Trata-se de survey pós-eleitoral aplicado em todo o território nacional. Foram realizadas 2514 entrevistas.

3 Pesquisa nacional coordenada pelos professores Dr. José Álvaro Moisés (NUPPS e DCP. Universidade de São Paulo) e Dra. Rachel Meneguello (CESOP e DCP . Unicamp) e financiada pela FAPESP. A pesquisa realizou 2004 entrevistas nacionais em junho de 2006.

${ }^{4}$ Adhemar de Barros (1901-1969) foi interventor e governador do estado de São Paulo, deputado estadual e prefeito da cidade de São Paulo. Paulo Maluf (1931-) foi governador do estado de São Paulo e prefeito da cidade de São Paulo. Atualmente é deputado federal. 
BONIFÁCIO, R. A afeição dos cidadãos pelos políticos mal-afamados: identificando...

A Tabela 1 ilustra que, em todas as variáveis, há mais rechaçamento do que aprovação das situações postas em análise, ou seja, as discordâncias superam as concordâncias. Esse cenário é mais intenso para os dados de 2006:

Tabela 1

Frequência das variáveis indicadoras de "rouba, mas faz" (\%)

\begin{tabular}{|c|c|c|c|c|c|c|c|}
\hline \multicolumn{8}{|c|}{ ESEB 2002} \\
\hline & $\begin{array}{l}\text { Discorda } \\
\text { muito }\end{array}$ & $\begin{array}{l}\text { Discorda } \\
\text { pouco }\end{array}$ & $\begin{array}{l}\text { Não concorda } \\
\text { nem discorda }\end{array}$ & $\begin{array}{l}\text { Concorda } \\
\text { pouco }\end{array}$ & $\begin{array}{c}\text { Concorda } \\
\text { muito }\end{array}$ & NS/NR & Total \\
\hline $\begin{array}{l}\text { Um político que faz um } \\
\text { bom governo deve poder } \\
\text { desviar dinheiro público } \\
\text { para financiar sua } \\
\text { campanha eleitoral }\end{array}$ & 72,8 & 8,2 & 0,3 & 6,5 & 8,0 & 4,2 & 100 \\
\hline $\begin{array}{l}\text { Um político que faz muito } \\
\text { e rouba um pouco merece } \\
\text { o voto da população }\end{array}$ & 43,3 & 12,8 & 0,9 & 19,7 & 19,7 & 3,6 & 100 \\
\hline $\begin{array}{l}\text { É melhor um político que } \\
\text { faça muitas obras, mesmo } \\
\text { que roube um pouco, do } \\
\text { que um político que faça } \\
\text { poucas obras e não roube } \\
\text { nada }\end{array}$ & 42,8 & 12,7 & 1,0 & 18,2 & 21,4 & 3,9 & 100 \\
\hline $\begin{array}{l}\text { Não faz diferença se um } \\
\text { político rouba ou não, o } \\
\text { importante é que ele faça } \\
\text { as coisas que a população } \\
\text { precisa }\end{array}$ & 52,8 & 9,9 & 0,8 & 14,5 & 18,9 & 3,1 & 100 \\
\hline \multicolumn{8}{|c|}{ DESCONFIANÇA 2006} \\
\hline $\begin{array}{l}\text { O melhor político é o que } \\
\text { faz muitas obras e } \\
\text { realizações, mesmo que } \\
\text { roube um pouco }\end{array}$ & 72,3 & 8,8 & 2,2 & 11,7 & 4,5 & 0,5 & 100 \\
\hline $\begin{array}{l}\text { Um político que faz um } \\
\text { bom governo deve poder } \\
\text { desviar dinheiro público } \\
\text { para financiar sua } \\
\text { campanha eleitoral }\end{array}$ & 79,4 & 9,4 & 2 & 6,3 & 2,4 & 0,5 & 100 \\
\hline $\begin{array}{l}\text { Um político que faz muito } \\
\text { e rouba um pouco não } \\
\text { merece ser condenado } \\
\text { pela justiça }\end{array}$ & 74,3 & 10,5 & 2,2 & 8 & 4,5 & 0,5 & 100 \\
\hline $\begin{array}{l}\text { Um político que faz muito } \\
\text { e rouba um pouco merece } \\
\text { o voto da população }\end{array}$ & 72,7 & 9,3 & 1,8 & 10,5 & 5,3 & 0,4 & 100 \\
\hline $\begin{array}{l}\text { Não faz diferença se um } \\
\text { político rouba ou não, o } \\
\text { importante é que ele faça } \\
\text { as coisas que a população } \\
\text { precisa }\end{array}$ & 72,7 & 9 & 1,5 & 10,3 & 6,2 & 0,3 & 100 \\
\hline
\end{tabular}

Fonte: “Estudo Eleitoral Brasileiro" (2002) e "A Desconfiança dos Cidadãos das Instituições Democráticas" (2006).

A frase em que se observa maior discordância entre os entrevistados $(79,4 \%)$ é "Um político que faz um bom governo deve poder desviar dinheiro público para financiar sua campanha eleitoral" (Pesquisa Desconfiança, 2006 . Tabela 1). Isso significa usurpar o dinheiro público em benefício próprio, dinheiro que, no caso, desembocaria em sua campanha eleitoral. Já as frases com maiores níveis de 
concordância, em ambos os surveys, expressam indiferença em relação a atos corruptos de um político, desde que ele promova ações que ajudem a população. Em 2002, 39,6\% do total de entrevistados concordam muito ou pouco com a seguinte frase: "É melhor um político que faça muitas obras, mesmo que roube um pouco, do que um político que faça poucas obras e não roube nada". Em 2006, a mais alta concordância (16,5\%) é atribuída à frase: "Não faz diferença se um político rouba ou não, o importante é que ele faça as coisas que a população precisa".

De um modo geral, os percentuais de discordância são muito expressivos em todas as variáveis de ambas as pesquisas. Talvez a explicação para isso resida no distanciamento do público entrevistado às situações postas em análise. Em todos os casos, as frases referem-se ao ambiente de representação política, ao ofício dos representantes eleitos pelo povo. Tal contexto não faz parte do cotidiano dos entrevistados e, por isso, os julgamentos tendem a ser rigorosos. A ideia é que, por não se enxergarem nas situações, é pouco ou nada constrangedor externar opiniões críticas a respeito.

Pode-se afirmar que todos os indicadores do "rouba, mas faz" apresentam um sentido lógico bastante próximo entre si, ou seja, expressam uma mesma ideia. Contudo, para que se construam índices a respeito, é essencial um passo a mais: identificar relações estatísticas robustas entre as variáveis indicadoras.

Para tanto, o teste mais adequado é o de análise fatorial ${ }^{5}$. O método de extração mais recomendado para variáveis que não apresentam distribuição normal bem definida é o principal axis factoring (COSTElo; OsBoRne, 2005). Além disso, é importante que o alpha de Cronbach, um indicador de consistência interna do fator, tenha um expressivo patamar. Quanto maior o valor do alpha, maior é a correlação entre os itens que compõem o fator e, por consequência, maior o inter-relacionamento entre as variáveis (CRONBACH, 1951). Não há valores mínimos válidos definidos tanto para a carga estatística das variáveis nos fatores criados quanto para o valor de alpha de Cronbach. Contudo, boa parte dos estudos da área trabalha com valores mínimos de 0,5 e de 0,7 para as cargas estatísticas do primeiro e segundo fatores, respectivamente.

Os resultados presentes nas Tabelas 2 e 3 evidenciam a satisfação das condições. A única exceção é o indicador "Um político que faz um bom governo deve poder desviar dinheiro público para financiar sua campanha eleitoral", do survey de 2002. Entretanto, por possuir sentido lógico parecido ao das demais variáveis e por ter redação semelhante a um indicador presente de modo estatisticamente significante no survey de 2006, opta-se por sua manutenção para a construção do índice de "rouba, mas faz".

${ }^{5} \mathrm{O}$ teste de análise fatorial compõe-se de técnicas estatísticas que objetivam prover descrições simples de inter-relacionamento, correlações e covariâncias entre as variáveis. Ele torna visível a observação de quais variáveis possuem significativas associações entre si e as organiza em fatores. Em cada fator, temos as variáveis mais associadas entre si e a intensidade dessa associação, que se mostrará forte, mediana ou fraca de acordo com a magnitude de sua carga estatística, geralmente compreendida entre - 1 e 1 (KIM; MuelleR, 1978). 
BONIFÁCIO, R. A afeição dos cidadãos pelos políticos mal-afamados: identificando...

Tabela 2

Análise fatorial com variáveis indicadoras do "rouba, mas faz" (2002)

\begin{tabular}{|l|c|}
\hline Variáveis & Fator \\
\hline $\begin{array}{l}\text { Não faz diferença se um político rouba ou não, o importante é que ele faça as coisas que a } \\
\text { população precisa }\end{array}$ & 0,707 \\
\hline $\begin{array}{l}\text { É melhor um político que faça muitas obras, mesmo que roube um pouco, do que um político que } \\
\text { faça poucas obras e não roube nada }\end{array}$ & 0,657 \\
\hline $\begin{array}{l}\text { Um político que faz muito e que rouba um pouco merece o voto da população } \\
\text { campanha eleitoral } \\
\text { Alpha de Cronbach=0,702 }\end{array}$ & 0,666 \\
\hline Fonte: “Estudo Eleitoral Brasileiro" (2002). & 0,399 \\
\hline
\end{tabular}

Tabela 3

Análise fatorial com variáveis indicadoras do "rouba, mas faz" (2006)

\begin{tabular}{|l|c|}
\hline Variáveis & Fator \\
\hline $\begin{array}{l}\text { Não faz diferença se um político rouba ou não, o importante é que ele faça as coisas que a } \\
\text { população precisa }\end{array}$ & 0,852 \\
\hline Um político que faz muito e que rouba um pouco merece o voto da população & 0,883 \\
\hline Um político que faz muito e rouba um pouco não merece ser condenado pela justiça & 0,798 \\
\hline $\begin{array}{l}\text { Um político que faz um bom governo deve poder desviar dinheiro público para financiar sua } \\
\text { campanha eleitoral }\end{array}$ & 0,743 \\
\hline O melhor político é o que faz muitas obras e realizações, mesmo que roube um pouco & 0,870 \\
\hline Alpha de Cronbach=0,916 & \\
\hline Fonte: “A Desconfiança dos Cidadãos das Instituições Democráticas” (2006). & \\
\hline
\end{tabular}

\section{Principais contribuições dos estudos na área}

Parte dos estudos do campo da Ciência Política sobre corrupção possui abordagens estritamente teóricas, buscando conceituar e definir a natureza e as características do fenômeno. Para Wraith e Simpkins (1963), por exemplo, a corrupção é entendida como uma incapacidade moral de certos cidadãos, algo deplorável e condenável. Já Nye (1967) possui uma concepção relativamente mais legalista do fenômeno, definindo corrupção como um comportamento desviante dos deveres formais da função pública com fins de ganhos monetários ou de status privado (para benefício pessoal, familiar ou de grupo próximo). Isso inclui comportamentos como suborno, nepotismo e apropriação de recursos públicos para benefícios privados. Por fim, existem estudos que situam a corrupção mais como um 
OPINIÃO PÚBLICA, Campinas, vol. 19, n², novembro, 2013, p. 320-345

problema de natureza econômica. Autores dessa vertente consideram que o monopólio de ação do governo abre oportunidades para ganhos econômicos excessivos por parte de grupos privados, o chamado rent seeking. O trabalho de Rose-Ackerman (1999) indica que a corrupção ocorre na interface dos setores público e privado, de acordo com sistemas de incentivo que permitem aos agentes políticos maximizarem utilidade mediante suborno e propina. Já para Tullock (1967), os agentes buscarão a maior renda possível, dentro ou fora das regras de conduta.

Estudos que tratam dos posicionamentos individuais sobre atos de corrupção de políticos como o aspecto a ser explicado são escassos. Todavia, é relativamente ampla a quantidade de estudos que investigam comportamentos e opiniões individuais em relação à corrupção em suas diversas formas. Estes são utilizados neste artigo como base para formulação de hipóteses e para a construção do desenho de análise empírica. O conjunto dos estudos selecionados aponta para cinco principais fatores explicativos: 1) a confiança em atores e instituições representativas; 2) a avaliação de atores e instituições representativas; 3) as condições socioeconômicas e demográficas; 4) a exposição a conteúdos midiáticos e 5) os "vencedores" e "perdedores" de disputas eleitorais.

1. Confiança em atores e instituições representativas

Para Offe (1999), confiar em instituições supõe conhecer a ideia básica ou a função permanente atribuída a elas pela sociedade, por exemplo, a crença de que a polícia existe para garantir a segurança e a vida das pessoas. Assim, a confiança política dos cidadãos não é cega ou automática, ela depende das instituições estarem estruturadas para permitir que eles conheçam, recorram ou interpelem os seus fins últimos, que são aceitos e desejados pelos cidadãos.

Congruente com o raciocínio de Offe, Moisés (2010) define confiança como a crença das pessoas na ação futura dos outros. Logo, envolve riscos porque não assegura necessariamente certeza quanto aos resultados. Pertinente à esfera da política, ela envolve a crença e as expectativas das pessoas a respeito das funções singulares atribuídas às instituições no regime democrático, algo diretamente relacionado à sua qualidade.

Moisés e Carneiro (2008; 2010) procuram evidências empíricas no caso brasileiro para as suposições teóricas anteriormente indicadas. Investigam, dentre outras coisas, a associação entre desconfiança institucional e apoio ao regime democrático. Um dos seus principais achados indica que aqueles que desconfiam das instituições, comparados aos que confiam, apresentam menor preferência pelo regime democrático, embora a desconfiança não esteja associada à preferência pelo autoritarismo. A desconfiança também se relaciona à aceitação de desenhos institucionais que não incorporam instituições representativas, como o congresso nacional e partidos políticos.

Os estudos citados levantam a ideia de que a desconfiança é elemento importante para entender orientações políticas. Também sugerem que ela está relacionada a opiniões que privilegiam o arcabouço institucional com escassez democrática, caso se considere a noção de que as instituições representativas são peças essenciais do arranjo democrático.

Seguindo as argumentações de Offe (1999) e Moisés (2010), pode-se considerar que o indivíduo que desconfia das instituições públicas apresenta enraizadas frustrações em relação ao 
BONIFÁCIO, R. A afeição dos cidadãos pelos políticos mal-afamados: identificando...

ambiente político, já que sua desconfiança é formada por um longo repertório de experiências e informações negativas em relação àquelas instituições. Tendo esse cenário como o mais realístico, é esperado que os indivíduos que desconfiam das instituições, além de possuírem pouca afeição ao ideal democrático, apresentem também maiores disposições de possuírem opiniões divergentes ao ideário usual de boa governança, que inclui transparência e honestidade no exercício de cargos públicos. Isso abre margem à suposição de que os desconfiados são menos dispostos a condenarem a ideia de "rouba, mas faz" do que aqueles em situação oposta. Desse modo, é possível formular a seguinte hipótese:

H1: Cidadãos que desconfiam de instituições e atores representativos apresentam relativamente mais afeição à ideia de "rouba, mas faz" do que aqueles que confiam nas instituições e atores representativos.

\section{2- Avaliações de instituições e atores representativos}

Conforme destacado anteriormente, a confiança institucional forma-se através das avaliações em relação ao desempenho, além dos julgamentos quanto a consistência e coerência interna das normas das instituições. Assim, não exprime mera satisfação, mas também saciamento de expectativas normativas pelas próprias instituições. Já a avaliação institucional pode ser entendida como um indicador de qualidade do desempenho da instituição arguida. E os critérios têm caráter momentâneo e são focados no sucesso de suas ações. Logo, confiança e avaliação institucional não podem ser entendidas como uma mesma coisa, pois exprimem lógicas distintas.

Essas suposições lógicas podem ser verificadas estatisticamente, através do teste de análise fatorial. Como os dois conjuntos de variáveis encontram-se presentes somente no survey de 2006, o teste só é aplicado ao mesmo. Os resultados, inseridos na Tabela 4, explicitam a formação de dois fatores e, em cada um deles, as cargas estatísticas são robustas. O primeiro fator agrega as maiores cargas estatísticas das variáveis sobre avaliação institucional e o segundo fator, às relativas a variáveis de confiança institucional. Assim, pode-se interpretar que essas variáveis expressam coisas diferentes.

Tabela 4

Análise fatorial com variáveis indicadoras de avaliação e confiança em atores e instituições representativas (2006)

\begin{tabular}{|c|c|c|}
\hline Variáveis & Fator 1 & Fator 2 \\
\hline Avaliação do congresso nacional & 0,642 & 0,224 \\
\hline Avaliação dos partidos políticos & 0,609 & 0,230 \\
\hline Avaliação do governo & 0,807 & 0,226 \\
\hline Avaliação do presidente & 0,718 & 0,262 \\
\hline Confiança no congresso nacional & 0,210 & 0,744 \\
\hline Confiança nos partidos políticos & 0,163 & 0,729 \\
\hline Confiança no governo & 0,339 & 0,714 \\
\hline Confiança no presidente & 0,388 & 0,601 \\
\hline
\end{tabular}


Quanto à importância da avaliação, Easton (1965) fornece importantes indicações. Ele alerta para a existência de dois tipos distintos de apoio ao regime: específico e difuso. O primeiro consiste no nível de satisfação dos cidadãos com os outputs (ações, respostas) dos governos, sendo, portanto, intimamente ligado à ideia de avaliações de políticas públicas, de instituições e ações governamentais. Isso significa que, em parte, o apoio ao sistema depende do quanto os cidadãos são persuadidos de que outputs governamentais atendem de fato às suas demandas em um tempo razoável. 0 autor compreende que a história política demonstra que muitos regimes se mantiveram mesmo em períodos de crise, o que é um forte indicador de que apenas satisfação com ações dos governos não basta para explicar o apoio ao sistema político. Por isso, considera haver outro tipo de apoio, o apoio difuso, que é formado por atitudes e valores que favorecem a existência e a manutenção do regime democrático. Tal apoio é constituído por aspectos psicológicos e simbólicos e funciona como um reservatório de legitimidade do sistema, ajudando-o a se manter mesmo em situações onde os outputs se mostram escassos ou mal avaliados.

O que Easton esclarece é que as avaliações sobre as ações do governo são importantes na constituição de apoio ao sistema político, apesar de não se constituírem como o único elemento explicativo. A despeito da grande reverberação que tiveram as considerações do autor, não é comum encontrar estudos que foquem na importância das avaliações de instituições para as orientações políticas, em especial àquelas relacionadas à corrupção. Resta, portanto, o exercício de relacioná-los logicamente, a fim de criarem-se hipóteses válidas. É de se esperar que um indivíduo que avalie negativamente as instituições também avalie negativamente os políticos que incorrem em atos que fogem à regra de boa conduta de um governante. Isso porque os políticos são os atores centrais das instituições representativas e, como tais elementos aparentam ser visivelmente ligados entre si, é de se esperar que a momentânea insatisfação com qualquer um desses elementos se alastre para os demais. Considerando esses pontos, tem-se a seguinte hipótese:

H2: Cidadãos que avaliam negativamente as instituições e atores representativos apresentam relativamente menos afeição à ideia de "rouba, mas faz" do que aqueles que as avaliam positivamente.

\section{Condições socioeconômicas e demográficas}

Há longa tradição de estudos que relacionam condições socioeconômicas e demográficas com orientações políticas dos indivíduos. Pode-se considerar que a consolidação desse tipo de estudo se dá a partir de meados do século passado, com destaque às obras de comportamento eleitoral feitas por politólogos estadunidenses. Como exemplo, pode-se citar a de Lazarsfeld, Berelson e Gaudet (1948), que investigaram os possíveis efeitos da mídia na decisão de voto, mas acabaram encontrando que as condições socioeconômicas objetivas são o principal fator explicativo do voto entre eleitores de uma cidade estadunidense.

No Brasil, a realização de tais estudos também é prática comum entre os politólogos. A obra de Castro (1997) traz um panorama das principais contribuições a respeito. Ela enfatiza que os principais achados dos estudos mais representativos sugerem que há relação entre ambiente relativamente mais 
BONIFÁCIO, R. A afeição dos cidadãos pelos políticos mal-afamados: identificando...

desenvolvido e maiores níveis de identificação partidária; que a maioria dos eleitores não faz a escolha do voto motivada por questões ideológicas; que os cidadãos com maiores níveis de status socioeconômicos são os mais informados sobre política e que os desenvolvimentos social, político e econômico não foram capazes de abolir as relações políticas clientelistas. Como consideração final de seu estudo, Castro sugere que, apesar de importantes, os fatores socioeconômicos e demográficos não bastam para compreender as motivações do comportamento eleitoral e da preferência partidária dos brasileiros.

Com relação às orientações políticas direcionadas a questões sobre corrupção, o estudo de Almeida (2007) é uma importante referência. O autor focaliza os posicionamentos dos cidadãos brasileiros em relação a várias questões, como "jeitinho brasileiro", sexualidade, visões sobre o Estado, racismo, política de cotas, etc. e seu principal objetivo é testar empiricamente as teses que Roberto DaMatta faz sobre a sociedade brasileira em dois de seus livros, Carnavais, malandros e heróis (1997) e A casa e a rua (1985), tentando justificar as peculiaridades nacionais. Apesar das limitações, os achados de Almeida são úteis para este artigo, pois versam sobre relações de variáveis socioeconômicas e demográficas com orientações políticas relacionadas à corrupção, a saber, o "jeitinho"6.

Almeida define o "jeitinho" como um instrumento que permite a quebra das regras estabelecidas. Para tentar medi-lo, pede que os entrevistados classifiquem como favor, corrupção ou jeitinho algumas situações propostas. São frases que expressam situações rotineiras na vida dos cidadãos e, ao contrário das afirmações usadas para medir o "rouba, mas faz", não se referem exclusivamente aos políticos, mas a atores sociais diversos, como os funcionários públicos, os policiais e os próprios cidadãos. As variáveis relevantes para explicar a aceitação ao "jeitinho" são idade, região de moradia e escolaridade. O local de moradia e o pertencimento ao mercado formal de trabalho, por sua vez, não têm influência.

Em relação à idade, há uma inflexão importante a partir de 45 anos de idade, onde passa a predominar a concepção de que o "jeitinho" é errado, ao contrário do que ocorre nas faixas de idade anteriores. Há diferenças regionais importantes, pois os moradores do norte e nordeste tendem a ver o jeitinho como algo certo, ao passo que os moradores do sul e sudeste tendem a vê-lo como algo errado. Quanto à instrução, nota-se que, quanto mais anos de estudo o indivíduo tem, menor a tolerância em relação ao "jeitinho". Há, porém, uma ressalva importante: o ponto principal de inflexão nesse julgamento está no nível mais elevado de instrução, o ensino superior. Almeida entende que a escolaridade é o principal fator explicativo dentre todos os demais.

O trabalho de Winters e Weitz-Shapiro (2010) também é uma importante contribuição para a construção de hipóteses deste artigo. Os autores baseiam-se em um survey nacional conduzido pelo

\footnotetext{
6 Para Fialho (2008), o livro "A cabeça do brasileiro", apesar de ser uma obra pioneira no que se refere a mapear as opiniões, os costumes e as "visões de mundo" dos brasileiros, possui muitas deficiências. Segundo o autor, Almeida demonstra, por exemplo, pouca profundidade analítica para explicar os efeitos da escolaridade nas questões postas em análise; raramente realiza discussões teóricas e testes de hipóteses antes da operacionalização dos dados; não inclui informações auxiliares e medidas de associação nas tabelas construídas; não faz testes multivariados para verificar relações entre as variáveis e realiza poucas comparações dos dados nacionais com os de outros países para quem almeja enfatizar as peculiaridades no comportamento do cidadão brasileiro.
} 
IBOPE em 2010 com 2002 cidadãos de todas as regiões do Brasil e que contém questões com características de testes experimentais para medir a aceitação dos entrevistados em relação à corrupção. Constroem uma situação hipotética para saber a opinião das pessoas sobre políticos corruptos, que é a seguinte:

"Imagine uma pessoa chamada Gabriel (ou Gabriela), que é uma pessoa como você, que vive em um bairro como a seu, mas em uma cidade diferente no Brasil. O prefeito da cidade de Gabriel (ou Gabriela) é candidato à reeleição em outubro. Ele é membro do PT (Partido dos Trabalhadores) \{ou PSDB [Partido da Democracia Brasileira Sociais]\}. Na cidade de Gabriel (ou Gabriela), é sabido que nunca o prefeito aceitou subornos (ou, frequentemente, aceitou subornos) ao fornecer contratos com o governo. O prefeito completou (poucos ou muitos, ou omitir toda a sentença) projetos de obras públicas durante seu mandato. Nesta cidade, a eleição para prefeito é esperado para acontecer em breve.

Na sua opinião, qual é a probabilidade de Gabriel votar para este prefeito na próxima eleição: muito provável, um pouco provável, improvável ou nada provável"?

Fonte: WINTERS, M.; WEITZ.SHAPIRO, R “'Rouba, mas faz' or not? Exploring voter attitudes toward corruption in Brazil". Trabalho apresentado no Annual Meeting of the American Political Science Association, Washington D.C, 2010.

O sexo da pessoa hipotética é sempre o mesmo da pessoa entrevistada. Já as distinções entre a filiação partidária do prefeito, a indicação de que ele é conhecido por aceitar subornos e a informação de que ele havia completado muitos ou poucos projetos de obras públicas foram itens atribuídos aleatoriamente aos indivíduos entrevistados. As seguintes combinações resultam da formulação dos autores: 2 (sexo) $\times 2$ (corrupto/ não corrupto) $\times 3$ (competências) = 12 tipos distintos de combinações.

Tabela 5

Combinações possíveis de opiniões referentes à corrupção

\begin{tabular}{|c|c|c|c|}
\hline & $\begin{array}{c}\text { Sem informações sobre } \\
\text { competência (obras) }\end{array}$ & $\begin{array}{c}\text { Baixa competência } \\
\text { (obras) }\end{array}$ & Alta competência (obras) \\
\hline Não corrupto & $\mathrm{B} 1(\mathrm{~N}=333)$ & $\mathrm{B} 2(\mathrm{~N}=335)$ & $\mathrm{B}(\mathrm{N}=334)$ \\
\hline Corrupto & $\mathrm{B} 4(\mathrm{~N}=331)$ & $\mathrm{B} 5(\mathrm{~N}=334)$ & $335)$ \\
\hline
\end{tabular}

Fonte: WINTERS, M.; WEITZ-SHAPIRO, R. "'Rouba, mas faz' or not? Exploring voter attitudes toward corruption in Brazil". Trabalho apresentado no Annual Meeting of the American Political Science Association, Washington D.C, 2010.

Observação: termos traduzidos pelo autor.

Caso a hipótese dos autores esteja correta, ou seja, se os eleitores reagem negativamente quando descobrem que um político é corrupto, então, espera-se observar menor propensão dos entrevistados em acharem que a pessoa hipotética votaria no prefeito suspeito de praticar corrupção, em comparação com a situação onde recaem dúvidas sobre a honestidade do prefeito. Assim, espera-se que o quantitativo das respostas siga a seguinte ordem: B4 <B1; B5< B2 e B6 <B3. Se, por outro lado, o "rouba, mas faz" é hipótese corroborada, ou seja, se os eleitores mostram maior propensão em achar que a pessoa hipotética votaria no prefeito considerado competente, porém corrupto, então, duas situações são esperadas: 1) menor "punição" do entrevistado ao prefeito corrupto, à medida que o seu 
BONIFÁCIO, R. A afeição dos cidadãos pelos políticos mal-afamados: identificando...

nível de competência aumenta e 2) maior preferência por prefeito corrupto, mas competente, que por prefeito incompetente não corrupto. Nesses dois casos, a ordenação dos quantitativos de respostas serão, respectivamente, B6 - B3 < B4 - B1 < B5 - B2 e B6 > B2.

Dentre os vários testes que realizam, os autores inserem posição de classe (utilizam os termos "pobres", "classe média" e "ricos") para observar diferenciações de comportamentos. A leitura dos dados indica que os entrevistados da classe alta parecem ser muito mais lenientes com políticos corruptos e muito mais tendentes a darem créditos aos políticos competentes. Ou seja, a tolerância a atos corruptos de políticos encontra-se mais espalhada entre os ricos.

Os dois estudos ajudam na formulação de hipóteses a serem testadas. Com base nos achados de Almeida (2007), podem-se formular as seguintes hipóteses:

H3: As aceitações do "rouba, mas faz" são maiores entre aqueles que possuem os menores níveis de instrução;

H4: As aceitações do "rouba, mas faz" são maiores entre os jovens do que entre os idosos.

Em ambos os estudos há achados contraditórios em relação à renda. Se, por um lado, no trabalho de Almeida (2007) a riqueza não está associada à tolerância ou intolerância ao "jeitinho", no artigo de Winters e Weitz-Shapiro (2010), há indicação de que os pertencentes à classe alta são os mais lenientes com políticos corruptos. A afirmação desses dois últimos autores vai em direção oposta à maior parte dos achados dos estudos de Sociologia Política. Em geral, renda e instrução são aspectos centrais nesses estudos, no sentido em que suas maiores taxas são associadas a maiores níveis de informação política, presença de ideologização e maiores patamares de civismo. De modo a se esquivar dos achados contraditórios dos estudos utilizados nesse tópico, segue-se as orientações gerais dos estudos de Sociologia Política e faz-se a seguinte hipótese:

H5: As aceitações do "rouba, mas faz" são menores entre aqueles que apresentam maiores rendas.

Aspectos importantes para o perfil socioeconômico e demográfico, tais como sexo, local de moradia e cor do entrevistado não são observados como relevantes para explicar o "jeitinho" na análise de Almeida e sequer são abordados no estudo de Winters e Weitz-Shapiro. Todavia, neste artigo, tais aspectos são incorporados às análises dos dados, devido à centralidade explicativa que apresentam em estudos da área de Sociologia Política em geral.

4- Exposição a conteúdo midiático

Quando se pensa em fontes de informação, é comum imaginar que a mídia ocupa pape destacado. O potencial da mídia para influenciar percepções dos indivíduos guarda relação com a centralidade que a comunicação de massa ocupa nas sociedades contemporâneas. Para além do oferecimento de informação factual, pode-se considerar também que a mídia constrói enquadramentos a partir dos quais o indivíduo cria mapas de referência para entender o mundo (GOFFMAN, 1986; IYENGAR; KINDER, 1987; CAPPELlA; JAMIeSON, 1997; AldÉ, 2004).

No que diz respeito às instituições, o sentido dos efeitos específicos da mídia não foi estabelecido de forma inequívoca. A acusação de que os meios de comunicação favorecem a 
OPINIÃO PÚBLICA, Campinas, vol. 19, n², novembro, 2013, p. 320-345

desconfiança política e a desmobilização tem o endosso de gerações de pesquisadores (RoBINSON, 1976; Patterson, 1993; CAPpella; Jamieson, 1997; Putnam, 1995; 2001). O principal argumento é que a mídia cria uma representação das instituições que é especialmente crítica e negativa. No entanto, há evidências de que a exposição à mídia pode afetar o indivíduo também de forma positiva. Ela ampliaria seu nível de informação, interesse pela política e sentimento de eficácia subjetiva - isto é, a crença de que é capaz de influir na política - e diminuiria os custos para participar da vida pública. Isso se verificaria de maneira mais consistente no caso da exposição à mídia jornalística e não à mídia em geral (NEWTON, 1999; NORRIS, 1996; 2000).

No Brasil, estudos levantaram indícios de que a comunicação de massa não afeta o apoio às instituições em apenas um sentido. Schlegel (2005) encontrou associação positiva entre exposição à mídia jornalística e julgamento "de fundo", não imediato7, de políticos e partidos em 2002. No caso da avaliação da atuação de Congresso, governo e partidos, a associação foi negativa. No entanto, os dois grupos de associações não se confirmaram quando controlado o perfil sociodemográfico dos entrevistados. Mesquita (2008) constatou que, mesmo diante de cobertura com valência negativa para o governo federal envolvendo o "escândalo do mensalão" em 2005, a audiência do Jornal Nacional (JN) ${ }^{8}$ estava positivamente associada à satisfação com a democracia e à confiança no governo, no Presidente da República, nas Forças Armadas, no Poder Judiciário, nos empresários e nos bombeiros em 2006. 0 artigo também mostra influência do patamar de audiência à televisão em geral, medido em horas, sobre os efeitos do JN. O impacto do telejornal foi mais intenso quando era maior sua participação no consumo diário de exposição do individuo à televisão.

O artigo de Rennó (2007) também é relevante, uma vez que tece considerações sobre possíveis influências de informações políticas ${ }^{9}$ no comportamento eleitoral do brasileiro. $\mathrm{O}$ aspecto a ser explicado é o voto para presidente nas eleições de 2006 e os resultados apontam que os cidadãos que apresentam mais informação política tenderam a votar em maior proporção no principal candidato oposicionista (Alckmin), em comparação com o candidato da situação (Lula), cujo governo, à época, estava submerso em escândalos de corrupção, devido a denúncias de deslizes de integrantes de seu partido e da coalizão de forças partidárias apoiadoras do governo na administração de recursos federais. Entretanto, comparada com os demais elementos explicativos do modelo de análise, essa variável não se mostrou muito relevante.

O trabalho de Schlegel (2005) indica efeitos distintos da exposição à mídia, em certos casos contribuindo para avaliações positivas de algumas instituições e atores e, em outros, aprofundando as insatisfações. Já em Mesquita (2008), observamos que um período de cobertura jornalística marcado por notícias negativas em relação ao governo está associado a aumento de satisfação com democracia e confiança nas instituições. Por fim, Rennó (2007) destaca que informação política tem relevância na

7 O índice usado como variável dependente pelo autor contemplava questões como a concordância com a frase "Políticos muito honestos não sabem governar" ou "Os partidos só servem para dividir as pessoas".

8 Trata-se do principal telejornal do país. Em 2006, 52\% dos entrevistados no survey "Desconfiança" declaram assistir o JN quatro vezes ou mais por semana e $89,2 \%$ declaram assistir ao menos uma vez por semana.

9 Informação política é medida por um índice que soma respostas corretas a perguntas sobre conhecimento político, que não inclui informação específica sobre cada candidato ou partido (RENNÓ, 2007). 
BONIFÁCIO, R. A afeição dos cidadãos pelos políticos mal-afamados: identificando...

escolha do voto, mas em magnitude menor quando comparada a outros elementos explicativos. Nota-se que as contribuições disponíveis não apontam para uma direção unívoca, para um sentido claro dos efeitos de informações nas orientações políticas dos cidadãos brasileiros. Contudo, pode-se salientar que os mais informados tendem a fazer escolhas mais críticas do que os menos informados. É assim na avaliação da atuação de instituições investigadas por Schlegel e no voto no principal candidato a Presidente oposicionista a um governo marcado, à época, por denúncias de corrupção, identificado por Rennó. Logo, é possível estabelecer a seguinte hipótese:

H6: Há maior afeição pelo "rouba, mas faz" entre os que apresentam baixa exposição a conteúdo midiático, quando comparados aos que apresentam alta exposição a conteúdo midiático

5- "Vencedores" e "perdedores" de disputas eleitorais

Em período recente, tem sido comum especialistas investigarem se, e possivelmente o quanto, as escolhas eleitorais influenciam opiniões e atitudes após os pleitos. A ideia básica é que os "vencedores" (cidadãos que votaram na eleição anterior em candidatos a cargos políticos que foram eleitos) possuem visão mais positiva do sistema, instituições e atores políticos do que os "perdedores" (cidadãos que votaram na eleição anterior em candidatos a cargos políticos que não foram eleitos). As diferentes posições sobre o campo da política levariam, consequentemente, a distinções de atitudes e opiniões políticas.

Anderson e Guillory (1997) entendem que certas características estáveis da vida democrática, como as eleições, ajudam a organizar e a restringir as atitudes políticas dos cidadãos em relação ao funcionamento do sistema político. Aliado a isso, jogam luzes nas estruturas institucionais, que, para eles, possuem o papel de mediação de preferências. Assim, acreditam que ser "vencedor" ou "perdedor" em disputas eleitorais ajuda a explicar orientações políticas.

O objetivo dos autores é verificar se essas suposições se aplicam às satisfações com o funcionamento da democracia entre cidadãos de países da Europa Central e Oriental (Bélgica, Dinamarca, França, Grã-Bretanha, Grécia, Irlanda, Holanda, Itália, Portugal, Espanha e Alemanha Ocidental) no ano de 1990. Primeiramente, observam que os "vencedores" mostram-se mais satisfeitos com a democracia do que os "perdedores". Em seguida, apoiam-se nas definições de Lijphart (1984; 1994 apud ANDERSON \& GUILLORY (1997)) sobre sistemas políticos consensuais e majoritários e utilizam essas variáveis agregadas como possíveis mediadoras da relação entre "vencedores" / "perdedores" e satisfação com democracia. Verificam que, quanto mais consensual é o sistema político, menores são as insatisfações dos "perdedores" com a democracia e menores são as satisfações dos "vencedores". A situação é oposta para países que possuem sistema político com feições majoritárias. A partir desses achados, os autores afirmam que os estudos sobre satisfação com democracia devem levar em consideração elementos explicativos em níveis individual e institucional e que é importante focar-se nos possíveis efeitos de mediação que os últimos desempenham na relação.

Norris (1999) se atém ao mesmo problema de pesquisa, apesar de ter objetivo distinto: tenta explicar a confiança institucional em um conjunto mais variado de países com base nas ondas de 1980 . 
OPINIÃO PÚBLICA, Campinas, vol. 19, n², novembro, 2013, p. 320-345

84 e 1990-93 do World Values Survey. Identifica em todos os países que os "vencedores" apresentam maiores taxas de confiança do que os "perdedores", sendo a França a única exceção. As maiores diferenças nas taxas de confiança ocorrem em países onde os governos foram comandados por um único partido durante longo período (Japão, México e Itália). Esses e demais resultados que a autora encontra a fazem ressaltar que as instituições importam para entender orientações políticas individuais e os modelos explicativos devem comportar variáveis de níveis micro e macro.

Com base nas argumentações de Tversk e Kahneman (1992), Anderson e Lotempio (2002) afirmam que os votantes preferem ser vitoriosos a derrotados e que os insucessos pesam mais do que os sucessos. Se a ideia for válida, acreditam que uma consequência natural seria essa situação de "vencedor" e "perdedor" afetar orientações relativas ao sistema político. Para tentarem comprovar a ideia, os autores utilizam dados do National Election Survey de 1972 e 1996 para investigarem se há distinção na confiança política dos "vencedores" e dos "perdedores" entre os estadunidenses.

Os resultados confirmam uma de suas hipóteses: os "vencedores" apresentam maiores taxas de confiança política do que os "perdedores". Contudo, não se observa magnitude de efeitos em forma ordinal, conforme indicado na hipótese dois: os autores criam quatro tipificações de votantes, com base em sucessos e insucessos nas eleições presidenciais e congressuais (câmara e senado) e o tipo duplamente vitorioso ("vencedor" na eleição presidencial e congressual) não possui maiores taxas de confiança do que o tipo vencedor parcial presidencial (aquele que vence a eleição presidencial, mas é perdedor na eleição congressual). Os achados vão em direção aos já encontrados por Anderson e Guillory (1997), indicando que o fato de as pessoas serem "vencedoras" ou "perdedoras" em pleitos eleitorais ajuda a entender o ambiente político e a explicar atitudes políticas subsequentes.

Tais estudos são úteis para os objetivos deste artigo, uma vez que seus resultados tornam possível imaginar que os "vencedores" de uma eleição tendem a possuir visão mais positiva acerca do governo subsequente do que os "perdedores". Essa visão positiva pode influenciar as orientações políticas, incluindo a aceitação da ideia do "rouba, mas faz". A convicção dos votantes de que seu candidato a cargo político vencedor é a melhor das opções lançadas e/ ou o perfil mais adequado para assumir o governo pode implicar avaliações enviesadas de seu desempenho. Tal situação pode levar, por exemplo, a níveis altos de afeição pelo político, a tal ponto de desconsiderar a importância das práticas corruptas por ele praticadas. Assim, é plausível supor que os "vencedores" acreditam com maior intensidade do que os "perdedores" que a imersão em corrupção pelo político incumbente é minorada pelas ações positivas realizadas ao longo do governo. Logo, é possível formular a seguinte hipótese:

H7: Os "vencedores" apresentam maior aceitação à ideia de "rouba, mas faz" do que os "perdedores".

\section{Procedimentos Metodológicos}

A análise empírica do artigo está baseada nos surveys "Estudo Eleitoral Brasileiro (ESEB)", de 2002 e "A Desconfiança dos Cidadãos das Instituições Democráticas", de 2006. Nesta seção, descrevem. se as variáveis dependentes e independentes de cada survey, utilizadas nos testes de regressão logística a serem expostos na próxima seção. 
BONIFÁCIO, R. A afeição dos cidadãos pelos políticos mal-afamados: identificando...

1- Estudo Eleitoral Brasileiro (ESEB), 2002

Variável dependente:

* Índice de "rouba, mas faz": constituído das variáveis descritas no Quadro 1. Foi atribuído valor 1 (um) às opções de respostas que indicavam favorecimento da ideia de "rouba, mas faz" e valor 0 (zero) para as demais. A partir daí, foi feita uma soma entre as variáveis, resultando na formação de outra, que contém valores de 0 a 4 . Após isso, criou-se o índice, uma variável de tipo qualitativa ordinal, onde o valor zero corresponde a "nenhuma aceitação", os valores 1 e 2 indicam "moderada aceitação" e os valores 3 e 4 expressam "forte aceitação" à ideia de "rouba, mas faz". A descrição da variável encontra. se na Tabela 6:

\section{Tabela 6}

Índice de "rouba, mas faz" (2002)

\begin{tabular}{|l|c|c|c|}
\hline & Frequência & Percentual & Percentual válido \\
\hline Nenhuma aceitação & 886 & 35,3 & 37,7 \\
\hline Moderada aceitação & 934 & 37,2 & 39,7 \\
\hline Forte aceitação & 531 & 21,1 & 22,6 \\
\hline Total & 2351 & 93,5 & 100 \\
\hline Valores ausentes & 162 & 6,5 & \\
\hline Total & 2513 & 100 & \\
\hline
\end{tabular}

Variáveis independentes:

* Avaliações de atores e instituições representativas: congresso nacional, partidos políticos e governo federal: avaliações negativa e regular/positiva;

* Características socioeconômicas e demográficas: a) sexo masculino e feminino; b) cor branca e demais; c) faixas de idade: de 16 a 24; 25 a 34; de 35 a 45; de 46 a 59 e mais de 60 anos; d) renda familiar mensal: até um salário mínimo; mais de um até cinco salários mínimos e mais de cinco salários mínimos; e) faixas de níveis de instrução: analfabeto/ primário incompleto e completo; fundamental incompleto/ completo; médio incompleto/ completo; superior incompleto ou mais e f) local de residência: cidades do interior e capitais.

* Exposição a conteúdo midiático: a) consumo de televisão diário: não costuma assistir/ até 1 hora; de 2 a 3 horas e 4 horas ou mais.

* "Vencedores" / "perdedores": Voto nas últimas eleições presidenciais: voto nos candidatos perdedores e voto no candidato vencedor.

\section{A Desconfiança dos Cidadãos das Instituições Democráticas, 2006}

Variável dependente:

* Índice de "rouba, mas faz": constituído das variáveis descritas no Quadro 1. Foi atribuído valor 1 (um) às opções de respostas que indicavam favorecimento da ideia de "rouba, mas faz" e valor 0 (zero) para as demais. A partir daí, foi feita uma soma entre as variáveis, resultando na formação de outra, que contém valores de 0 a 5 . Como as frequências dos itens que expressam valor de 1 a 5 mostram-se relativamente baixas $(37,7 \%)$ para formar duas categorias - como feito na pesquisa de 2002 -, decidiu-se 
OPINIÃO PÚBLICA, Campinas, vol. 19, n², novembro, 2013, p. 320-345

pela junção de todos esses itens em uma única opção de resposta do índice, qual seja, "alguma aceitação" à ideia de "rouba, mas faz". Ao item com valor zero foi atribuída a designação "nenhuma aceitação". A descrição do índice de "rouba, mas faz" utilizado encontra-se na Tabela 7:

Tabela 7

Índice de "rouba, mas faz" com duas categorias (2006)

\begin{tabular}{|c|c|c|c|}
\hline & Frequência & Percentual & Percentual válido \\
\hline Nenhuma aceitação & 1237 & 61,7 & 62,3 \\
\hline Alguma aceitação & 749 & 37,3 & 37,7 \\
\hline Total & 1986 & 99 & 100 \\
\hline Valores ausentes & 18 & 1,0 & \\
\hline Total & 2004 & 100 & \\
\hline
\end{tabular}

Variáveis independentes:

* Confiança em atores e instituições representativas: congresso nacional, partidos políticos, governo federal e Presidente da República: pouca/ nenhuma e alguma/ muita;

* Avaliações de atores e instituições representativas: congresso nacional, partidos políticos, governo federal e Presidente da República: avaliações negativa e regular/positiva;

* Características socioeconômicas e demográficas: a) sexo masculino e feminino; b) cor branca e demais; c) faixas de idade: de 16 a 24; 25 a 34; de 35 a 45; de 46 a 59 e mais de 60 anos; d) renda familiar mensal: até um salário mínimo; mais de um até cinco salários mínimos e mais de cinco salários mínimos; e) faixas de níveis de instrução: analfabeto/ primário incompleto e completo; fundamental incompleto/ completo; médio incompleto/ completo; superior incompleto ou mais e f) local de residência: cidades do interior e regiões metropolitanas/ capitais.

* Exposição a conteúdo midiático: a) consumo de televisão diário: não costuma assistir/ até 1 hora; de 2 a 3 horas e 4 horas ou mais e b) quantidade de dias na semana em que assiste Jornal Nacional: nenhum dia/ até 1 dia; de 2 a 3 dias; 4 ou mais dias.

* "Vencedores" / "perdedores": Voto nas últimas eleições presidenciais: voto nos candidatos perdedores e voto no candidato vencedor.

\section{Resultados}

Para análise dos dados, foram realizados testes de regressão logística, onde se analisa a associação entre cada variável independente com a dependente, tendo um conjunto de variáveis independentes elencadas. Para o ano de 2002, foi aplicada a regressão logística multinomial e, para o ano de 2006, a regressão logística binária. A leitura dos resultados nos dois casos ocorre em termos de chances de sucesso e com dois valores de referência, expressos tanto nas categorias da variável dependente ("moderada" ou "forte aceitação", em referência a nenhuma aceitação para 2002 e "alguma aceitação" em relação a nenhuma aceitação, em 2006) quanto nas variáveis independentes (a categoria de resposta selecionada como valor de referência). Assim, o efeito percentual de qualquer variável independente sempre deve ser relacionado: 1) à categoria de resposta da variável independente selecionada como referência e 2) à categoria de resposta de referência da variável dependente, que é 
BONIFÁCIO, R. A afeição dos cidadãos pelos políticos mal-afamados: identificando...

sempre a que indica "nenhuma aceitação" ao “rouba, mas faz'”. A leitura dos dados é a mesma para qualquer um dos dois tipos de regressão ${ }^{10}$.

Para cada ano foram construídos três modelos de análise. Isso ajuda a observar o quanto as incorporações de variáveis independentes ao modelo inicial (1) aumentam a sua capacidade explicativa. Para o ano de 2002 (Tabelas 8 e 9), foram construídos três modelos: o modelo 1 contém variáveis que expressam características socioeconômicas e demográficas; o modelo 2 incorpora variáveis sobre avaliações de instituições e atores representativos e o modelo 3 adiciona variáveis de exposição a conteúdo midiático e "vencedores" e "perdedores" da eleição presidencial anterior. Para o ano de 2006 (Tabela 10), também são três modelos, mas o segundo contém, além das variáveis avaliativas, as de confiança nas mesmas instituições e atores representativos, e no modelo 3 há a incorporação de uma variável relativa à exposição a conteúdos midiáticos.

Referente aos dados do survey de 2002, observa-se que o teste que possui forte aceitação do "rouba, mas faz" como categoria a ser explicada (Tabela 9) apresenta mais variáveis independentes estatisticamente significantes. Também é possível perceber que, nas duas tabelas (8 e 9), quase todas as variáveis que expressam características socioeconômicas e demográficas estão associadas de modo estatisticamente significante com a variável a ser explicada (exceção para as que indicam sexo e local de residência do entrevistado). As variáveis sobre níveis de instrução, em especial a categoria que indica analfabetismo e primário incompleto ou completo, são as que contêm as maiores magnitudes percentuais em relação - que, nesse caso, possui sentido positivo - com a variável dependente.

Dentre as variáveis que mensuram avaliações negativas de instituições e atores representativos, apenas a relativa ao governo federal apresenta significância estatística, sempre em sentido negativo, isto é, de diminuição de chances de se ter moderada ou forte aceitação da ideia de "rouba, mas faz", em comparação às avaliações regulares e positivas. Já as variáveis que indicam exposição a conteúdos midiáticos e apontam os "vencedores" e "perdedores" da eleição presidencial anterior não aparecem associadas de modo estatisticamente significante com a categoria a ser explicada nos dois casos em análise.

$\mathrm{Na}$ leitura dos dados, mais dois aspectos merecem destaque: 1) nas situações em que a mesma variável independente aparece associada de modo estatisticamente significante para explicar moderada e forte aceitação à ideia de "rouba, mas faz", a magnitude percentual é sempre maior no segundo caso; 2) a incorporação de variáveis nos modelos sempre aumenta o valor de qui-quadrado para além dos valores críticos mínimos, considerando os graus de liberdade e valor alfa de 0,05. Isso significa que a incorporação das variáveis ajuda no aumento da capacidade explicativa ${ }^{11}$. Essa condição se mostra

10 Tomando como exemplo os resultados do modelo 1 da Tabela 8 para dados de 2002, observa-se que os entrevistados que declaram ser da cor branca possuem menos $36,4 \%$ de chances do que os entrevistados que declaram ser das demais cores de expressarem moderada aceitação da ideia de "rouba, mas faz", ao invés de expressarem nenhuma aceitação à ideia.

11 Os valores de qui-quadrado concedem noção de capacidade explicativa do modelo estatístico. Essa noção sempre se dá de modo comparativo, isto é, na comparação de um modelo com o outro. Em testes de regressão logística multinomial, deve-se multiplicar o número de categorias da variável dependente postas em interação (neste caso, duas: moderada e forte aceitação do "rouba, mas faz") com o número de categorias das variáveis independentes inseridas num novo modelo. Com posse do resultado, deve-se escolher um valor de alfa (o mais comum é 0,05) e consultar numa tabela de qui-quadrado o valor crítico correspondente. Se a diferença de valores obtida da subtração de um modelo com mais variáveis com modelo com menos variáveis for superior ao valor crítico observado na tabela, é possível concluir que a adição das variáveis ajuda a aumentar a 337 
OPINIÃO PÚBLICA, Campinas, vol. 19, n², novembro, 2013, p. 320-345

mais robusta no caso do modelo 2 em relação ao modelo 1, onde ocorre adição de variáveis sobre avaliações de instituições.

Tabela 8

Teste de regressão logística multinomial tendo "moderada aceitação ao rouba, mas faz" como categoria a ser explicada ${ }^{12}(2002)$

\begin{tabular}{|c|c|c|c|c|c|c|c|c|c|}
\hline & \multicolumn{3}{|c|}{ Modelo 1} & \multicolumn{3}{|c|}{ Modelo 2} & \multicolumn{3}{|c|}{ Modelo 3} \\
\hline Variáveis independentes & $B$ & P valor & $\begin{array}{l}\text { Efeito } \\
(\%)\end{array}$ & $B$ & $P$ valor & $\begin{array}{l}\text { Efeito } \\
(\%)\end{array}$ & $B$ & Pvalor & $\begin{array}{l}\text { Efeito } \\
(\%)\end{array}$ \\
\hline Intercepto & , 160 & . & & ,262 & . & & ,045 & & \\
\hline Masculino & $\cdot, 126$ & . & $\cdot 11,9$ &, 130 & . & $\cdot 12,2$ & -097 & . & 9,2 \\
\hline Cor branca &,- 452 & $* * *$ & $-36,4$ & ,470 & $* * *$ & $-37,5$ &,- 462 & $* * *$ & -37 \\
\hline 16 a 24 anos &, 031 & . & 3,1 &, 171 & $\cdot$ & 18,7 & $\cdot, 004$ & $\cdot$ & $.0,4$ \\
\hline 25 a 34 anos & ,115 & . & 12,2 & ,290 & - & 33,6 & ,421 & * & 52,3 \\
\hline 35 a 44 anos & ,065 & . & 6,7 & ,201 & - & 22,3 &, 350 & - & 42 \\
\hline 45 a 59 anos & $\cdot, 101$ & $\cdot$ & $\cdot 9,4$ & $\cdot, 044$ & - & $\cdot 4,3$ & ,068 & $\cdot$ & 7,1 \\
\hline $\begin{array}{l}\text { Analfabetos e primário } \\
\text { incompleto/ completo }\end{array}$ & ,704 & $* * *$ & 102,1 & ,797 & $* * *$ & 121,8 & ,882 & **** & 141,5 \\
\hline $\begin{array}{l}\text { Fundamental } \\
\text { incompleto/ completo }\end{array}$ & ,670 & $* * *$ & 95,4 & ,725 & **** & 106,6 & ,482 & ** & 62 \\
\hline $\begin{array}{l}\text { Ensino médio } \\
\text { incompleto/ completo }\end{array}$ & ,282 & . & 32,5 & ,339 & * & 40,3 & ,266 & - & 30,5 \\
\hline Mais de 1 até $5 \mathrm{SM}$ & $\cdot, 216$ & $\cdot$ & $\cdot 19,4$ & , 249 & $\cdot$ & $\cdot 22$ & $\cdot, 187$ & $\cdot$ & $\cdot 17,1$ \\
\hline Mais de $5 \mathrm{SM}$ &,- 526 & $* * *$ & $-40,9$ &,- 580 & * & -44 &,- 505 & $*$ & $-39,6$ \\
\hline Residente em capital & ,105 & $\cdot$ & 11,1 & ,122 & $\cdot$ & 13 & ,287 & $* *$ & 33,2 \\
\hline $\begin{array}{l}\text { Avaliação governo } \\
\text { federal: negativa }\end{array}$ & & & &,- 503 & **** & $-39,5$ &,- 579 & $* * *$ & -44 \\
\hline $\begin{array}{l}\text { Avaliação partidos } \\
\text { políticos: negativa }\end{array}$ & & & & ,094 & $\cdot$ & 9,9 & ,159 & $\cdot$ & 17,2 \\
\hline $\begin{array}{l}\text { Avaliação congresso: } \\
\text { negativa }\end{array}$ & & & & $\cdot, 043$ & - & $.4,2$ & ,024 & $\cdot$ & 2,4 \\
\hline $\begin{array}{l}\text { JN: nunca/ raramente/ } \\
1 \text { dia }\end{array}$ & & & & & & & ,014 & - & 1,4 \\
\hline JN: de 2 a 3 dias & & & & & & & $\cdot, 028$ & $\cdot$ & 2,8 \\
\hline "Vencedores" & & & & & & & ,027 & $\cdot$ & 2,8 \\
\hline Cox e Snell & 0,100 & & & 0,128 & & & 0,149 & & \\
\hline R de Nagelkerke & 0,114 & & & 0,145 & & & 0,170 & & \\
\hline Qui-quadrado & 722,6 & & & 2016 & & & 2302 & & \\
\hline
\end{tabular}

Fonte: Estudo Eleitoral Brasileiro (2002)

$*_{* *}^{*}=p$ valor $\leq 0,01 ; *^{*}=0,01<p$ valor $\leq 0,05 ; *=0,05<p$ valor $\leq 0,10$

capacidade explicativa do teste. No caso deste artigo, toda incorporação de variáveis nos modelos 2 e 3 das Tabelas 8 e 9 gera uma diferença de valor de qui-quadrado superior ao mínimo a ser alcançado, segundo valores indicados na tabela de quiquadrado. Vários livros de estatística possuem a tabela de qui-quadrado, que também pode ser consultada no seguinte endereço eletrônico: <http://www.ime.unicamp.br/ hlachos/TabelaQuiQuadrado.pdf>. Acesso em: 19 out. 2011.

12 Grupos de referência para cada variável independente: para sexo masculino, sexo feminino; para cor branca, demais cores; para níveis de instrução, ensino superior ou mais; para faixas de idade, mais de 60 anos; para renda, até um salário mínimo mensal; para residência; residir no interior; para avaliações, as regulares e positivas; para nível informacional, assistir Jornal Nacional quatro ou mais dias na semana. Essas informações também são válidas para a leitura dos dados da Tabela 9.

$$
338
$$


BONIFÁCIO, R. A afeição dos cidadãos pelos políticos mal-afamados: identificando...

Tabela 9

Teste de regressão logística multinomial tendo "forte aceitação ao rouba, mas faz" como categoria a ser explicada (2002)

\begin{tabular}{|c|c|c|c|c|c|c|c|c|c|}
\hline & \multicolumn{3}{|c|}{ Modelo 1} & \multicolumn{3}{|c|}{ Modelo 2} & \multicolumn{3}{|c|}{ Modelo 3} \\
\hline $\begin{array}{l}\text { Variáveis } \\
\text { independentes }\end{array}$ & $B$ & $P$ valor & $\begin{array}{l}\text { Efeito } \\
(\%)\end{array}$ & $B$ & Pvalor & $\begin{array}{l}\text { Efeito } \\
(\%)\end{array}$ & $B$ & Pvalor & $\begin{array}{l}\text { Efeito } \\
(\%)\end{array}$ \\
\hline Intercepto & $-1,2$ & $* * *$ & &,- 986 & $* *$ & & $-1,45$ & $* * *$ & \\
\hline Masculino & $\cdot, 197$ & . & $\cdot 17,9$ & $\cdot, 173$ & - & $\cdot 15,9$ & $\cdot, 236$ & . & .21 \\
\hline Cor branca &,- 624 & $* * *$ & $-46,4$ &,- 663 & $* * *$ & $-48,5$ &,- 823 & $* * *$ & $-56,1$ \\
\hline 16 a 24 anos & ,457 & * & 57,9 &, 592 & ** & 80,7 &, 685 & * & 98,3 \\
\hline 25 a 34 anos & ,365 & $\cdot$ & 44 &, 516 & * & 67,5 & ,769 & ** & 115,7 \\
\hline 35 a 44 anos & ,192 & . & 21,2 & ,297 & . & 34,5 & ,419 & . & 52 \\
\hline 45 a 59 anos & , 149 & - & 16,1 & ,306 & $\cdot$ & 35,8 &, 521 & $*$ & 68,4 \\
\hline $\begin{array}{l}\text { Analfabetos e } \\
\text { primário } \\
\text { incompleto/ } \\
\text { completo }\end{array}$ & 1,70 & $* * *$ & 451,9 & 1,68 & $* * *$ & 435,7 & 1,98 & $* * *$ & 626,6 \\
\hline $\begin{array}{l}\text { Fundamental } \\
\text { incompleto/ } \\
\text { completo }\end{array}$ & 1,60 & $* * *$ & 395,8 & 1,54 & $* * *$ & 365 & 1,58 & $* * *$ & 385,3 \\
\hline $\begin{array}{l}\text { Ensino médio } \\
\text { incompleto/ } \\
\text { completo }\end{array}$ & ,844 & $* * *$ & 132,5 & ,744 & ** & 110,3 & ,827 & $* *$ & 128,6 \\
\hline Mais de 1 até 5 SM & $\cdot, 287$ & $\cdot$ & $\cdot 25$ & $\cdot, 316$ & - & $\cdot 27,1$ & $\cdot, 308$ & $\cdot$ & $\cdot 26,9$ \\
\hline Mais de 5 SM &,- 834 & $* * *$ & $-56,6$ &,- 930 & $* * *$ & $-60,5$ &,- 720 & ** & $-51,3$ \\
\hline $\begin{array}{l}\text { Residente em } \\
\text { capital }\end{array}$ &, 017 & . & 1,7 &, 032 & - & 3,2 &, 157 & - & 17 \\
\hline $\begin{array}{l}\text { Avaliação governo } \\
\text { federal: negativa }\end{array}$ & & & &,- 544 & $* * *$ & -42 &,- 631 & $* * *$ & $-46,8$ \\
\hline $\begin{array}{l}\text { Avaliação partidos } \\
\text { políticos: negativa }\end{array}$ & & & &, 198 & - & 21,9 &, 189 & - & 20,8 \\
\hline $\begin{array}{l}\text { Avaliação } \\
\text { congresso: negativa }\end{array}$ & & & & $\cdot, 152$ & . & 14,1 & $\cdot, 175$ & . & $\cdot 16,1$ \\
\hline $\begin{array}{l}\text { JN: nunca/ } \\
\text { raramente/ } 1 \text { dia }\end{array}$ & & & & & & & ,116 & - & 12,3 \\
\hline JN: de 2 a 3 dias & & & & & & &, 118 & . & 12,5 \\
\hline "Vencedores" & & & & & & &, 174 & - & 19,1 \\
\hline Cox e Snell & 0,100 & & & 0,128 & & & 0,149 & & \\
\hline R de Nagelkerke & 0,114 & & & 0,145 & & & 0,170 & & \\
\hline Qui-quadrado & 722,6 & & & 2016 & & & 2302 & & \\
\hline
\end{tabular}

Fonte: Estudo Eleitoral Brasileiro (2002).

*** $=\mathrm{p}$ valor $\leq 0,01 ; * *$ * $=0,01<\mathrm{p}$ valor $\leq 0,05 ; *=0,05<\mathrm{p}$ valor $\leq 0,10$.

Os resultados das regressões aplicadas aos dados de 2006 (Tabela 10) apresentam muitas semelhanças em relação aos resultados obtidos com os dados de 2002. Observam-se associações de mesmo sentido nos dois anos para as variáveis independentes que expressam cor, idade, escolaridade e renda dos cidadãos entrevistados. As diferenças ficaram restritas às relações das variáveis de cunho 
avaliativo. Dentre os três casos que podem ser comparados (não há avaliação de presidente nos dados de 2002), em dois deles o sentido da associação com a variável dependente é oposto - congresso nacional e governo federal, que possuem relação de sentido negativo em 2002 e positivo em 2006 com aceitações da ideia de "rouba, mas faz" - e em apenas um há compatibilidade - relação de sentido positivo para partidos políticos. Quanto à frequência de acesso a informações noticiadas pelo Jornal Nacional, nos dois anos, predominam as associações positivas dos indicadores de menor frequência com a variável dependente, porém, para o ano de 2002, as relações não são estatisticamente significantes. Por fim, cabe enfatizar a dificuldade de se indicar qualquer tendência de relação entre variáveis relativas à confiança e aceitação da ideia de "rouba, mas faz". Em duas das quatro variáveis - desconfiança no congresso nacional e no Presidente, por sinal, a única estatisticamente significante - a associação se dá em direção negativa e, nas demais - confiança em partidos políticos e governo federal - ocorrem associações positivas.

Os dados para 2006 também apontam incremento no valor do qui-quadrado em cada modelo adicionado, o que indica aumento de capacidade explicativa. Comparativamente, a magnitude do aumento dos valores se dá de modo mais equilibrado que no ano de 2002. Nesse ano, a adição de valores do qui-quadrado é muito mais robusta do modelo inicial em relação ao modelo que incorpora variáveis avaliativas do que deste modelo para o que possui variáveis sobre informação política. Já em 2006, verificam-se aumentos de valores em patamares semelhantes: aumento de 140,45\% do modelo 1 para o modelo 2 e de $127,42 \%$ do modelo 2 para o modelo 3. Esses aumentos são significativos, uma vez que ultrapassam os valores críticos de qui-quadrado para o número de categorias das variáveis independentes inseridas ${ }^{13}$.

${ }^{13}$ Como já descrito na nota 11 , os valores de qui-quadrado concedem a noção de capacidade explicativa do modelo estatístico, noção essa que sempre se dá na comparação de um modelo com o outro. Em testes de regressão logística binária, deve-se multiplicar o número de categorias das variáveis independentes inseridas em um modelo por 3,84, o que gera o valor crítico do qui-quadrado. Em seguida, faz-se uma subtração do valor do qui-quadrado do modelo mais completo com o valor do modelo inicial. Se o valor resultante da subtração for superior ao do qui-quadrado crítico, há a indicação de que o modelo com mais variáveis tem maior capacidade explicativa do que o modelo inicial. 
BONIFÁCIO, R. A afeição dos cidadãos pelos políticos mal-afamados: identificando...

Tabela 10

Teste de regressão logística binária tendo "alguma aceitação ao rouba, mas faz" como categoria a ser explicada ${ }^{14}(2006)$

\begin{tabular}{|c|c|c|c|c|c|c|c|c|c|}
\hline \multirow[b]{2}{*}{$\begin{array}{l}\text { Variáveis } \\
\text { independentes }\end{array}$} & \multicolumn{3}{|c|}{ Modelo 1} & \multicolumn{3}{|c|}{ Modelo 2} & \multicolumn{3}{|c|}{ Modelo 3} \\
\hline & $B$ & $P$ valor & $\begin{array}{l}\text { Efeito } \\
(\%)\end{array}$ & $B$ & Pvalor & $\begin{array}{l}\text { Efeito } \\
(\%)\end{array}$ & $B$ & P valor & $\begin{array}{l}\text { Efeito } \\
(\%)\end{array}$ \\
\hline Intercepto &,- 894 & $* *$ & $-59,1$ &,- 751 & $*$ & $-52,8$ &,- 807 & $*$ & $-55,4$ \\
\hline Masculino &, 147 & $\cdot$ & 15,9 &, 144 & $\cdot$ & 15,5 &, 306 & $* *$ & 35,8 \\
\hline Cor branca &,- 316 & $* *$ & $-27,1$ &,- 302 & ** & $-26,1$ &,- 289 & $*$ & $-25,1$ \\
\hline 16 a 24 anos &, 420 & $*$ & 52,2 &, 506 & $*$ & 65,8 &, 498 & . & 64,6 \\
\hline 25 a 34 anos & ,203 & . & 22,5 &, 250 & - & 28,4 &, 320 & . & 37,8 \\
\hline 35 a 44 anos &, 115 & . & 12,2 &, 170 & $\cdot$ & 18,5 &, 193 & . & 21,3 \\
\hline 45 a 59 anos & $\cdot, 137$ & . & $.12,8$ &., 090 & 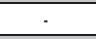 & $.8,6$ &., 023 & . & $.2,2$ \\
\hline $\begin{array}{l}\text { Analfabetos e primário } \\
\text { incompleto/ completo }\end{array}$ & ,713 & $* *$ & 104 & ,694 & $* *$ & 100 & ,632 & * & 88 \\
\hline $\begin{array}{l}\text { Fundamental } \\
\text { incompleto/ completo }\end{array}$ & ,497 & * & 64,4 & ,426 & . & 53,1 & ,461 & . & 58,6 \\
\hline $\begin{array}{l}\text { Ensino médio } \\
\text { incompleto/ completo }\end{array}$ & ,246 & . & 27,9 & ,221 & . & 24,7 &, 169 & . & 18,4 \\
\hline Mais de 1 até 5 SM &,- 303 & * & $-26,1$ & $\cdot, 258$ & . & $-22,7$ &,- 359 & $* *$ & $-30,2$ \\
\hline Mais de $5 \mathrm{SM}$ & $\cdot, 414$ & . & $.33,9$ & $\cdot, 333$ & . & $.28,3$ & $\cdot, 361$ & . & $-30,3$ \\
\hline $\begin{array}{l}\text { Residente em capital e } \\
\text { RM's }\end{array}$ &, 183 & . & 20,1 &, 063 & . & 6,5 & $\cdot, 107$ & . & $\cdot 10,2$ \\
\hline $\begin{array}{l}\text { Avaliação congresso: } \\
\text { negativa }\end{array}$ & & & &, 193 & . & 21,3 &, 174 & . & 19 \\
\hline $\begin{array}{l}\text { Avaliação partidos } \\
\text { políticos: negativa }\end{array}$ & & & & ,095 & . & 9,9 &, 166 & . & 18,1 \\
\hline $\begin{array}{l}\text { Avaliação governo: } \\
\text { negativa }\end{array}$ & & & & ,020 & $\cdot$ & 2 &, 045 & - & 4,6 \\
\hline $\begin{array}{l}\text { Avaliação presidente: } \\
\text { negativa }\end{array}$ & & & &,- 407 & $* *$ & $-33,4$ &,- 598 & $* * *$ & -45 \\
\hline $\begin{array}{l}\text { Desconfiança } \\
\text { congresso nacional }\end{array}$ & & & & $\cdot, 219$ & . & $-19,6$ & $\cdot, 282$ & . & $-24,5$ \\
\hline $\begin{array}{l}\text { Desconfiança partidos } \\
\text { políticos }\end{array}$ & & & &, 043 & . & 4,4 &, 006 & . & 0,6 \\
\hline Desconfiança governo & & & &, 330 & . & 39,1 & ,331 & . & 39,2 \\
\hline $\begin{array}{l}\text { Desconfiança } \\
\text { presidente }\end{array}$ & & & &,- 438 & $* *$ & $-35,5$ &,- 531 & $* *$ & $-41,2$ \\
\hline $\begin{array}{l}\text { JN: nunca/ raramente/ } \\
1 \text { dia }\end{array}$ & & & & & & &, 515 & $* *$ & 67,3 \\
\hline JN: de 2 a 3 dias & & & & & & & ,329 & * & 39 \\
\hline $\begin{array}{l}\text { Consumo diário de TV: } \\
\text { nada até } 1 \mathrm{~h}\end{array}$ & & & & & & & $\cdot, 029$ & . & $-2,8$ \\
\hline $\begin{array}{l}\text { Consumo diário de TV: } \\
\text { de } 2 \mathrm{~h} \text { a } 3 \mathrm{~h}\end{array}$ & & & & & & &, 126 & $\cdot$ & 13,5 \\
\hline "Vencedores" & & & & & & & $\cdot, 127$ & . & .12 \\
\hline Cox e Snell & 0,033 & & & 0,047 & & & & 0,068 & \\
\hline R de Nagelkerke & 0,045 & & & 0,064 & & & & 0,093 & \\
\hline Qui-quadrado & 35,62 & & & 50,03 & & & & 63,75 & \\
\hline
\end{tabular}

Fonte: A Desconfiança dos Cidadãos das Instituicões Democráticas (2006).

$*^{* *}=p$ valor $\leq 0,01 ; * *=0,01<p$ valor $\leq 0,05 ; *=0,05<p$ valor $\leq 0,10$.

14 Grupos de referência para cada variável independente: para sexo masculino, sexo feminino; para cor branca, demais cores: para níveis de instrução, ensino superior ou mais; para faixas de idade, mais de 60 anos; para renda, até um salário mínimo mensal; para residência; residir no interior; para avaliações, as regulares e positivas; para nível informacional, assistir Jornal Nacional quatro ou mais dias na semana e consumo diário de TV igual ou maior a quatro horas diárias e, para variáveis de desconfiança, ter alguma confiança em cada instituição analisada. 
OPINIÃO PÚBLICA, Campinas, vol. 19, n², novembro, 2013, p. 320-345

\section{Considerações Finais}

Após a exposição dos resultados, cabe verificar quais hipóteses são refutadas e corroboradas. Em relação à desconfiança de atores e instituições representativas, tem-se um cenário confuso, uma vez que somente uma das variáveis - desconfiança em Presidente - aparece associada de modo estatisticamente significante, em sentido negativo, com "alguma aceitação ao rouba, mas faz". Ademais, não há padrão no sentido das associações das quatro variáveis indicadoras, com duas delas apresentando associação negativa e duas delas associações positivas. Desse modo, torna-se difícil tecer considerações sobre a hipótese, sendo mais prudente realizar um estudo posterior com dados de variados anos para tentar chegar a resultados mais esclarecedores. O cenário é parecido para as variáveis de avaliações de atores e instituições representativas. Do mesmo modo, não há padrão no sentido das associações e sequer a maioria das variáveis possui relação estatisticamente significante com a variável dependente, nos dois anos pesquisados. Sendo assim, as respostas para as três primeiras hipóteses elaboradas ficam em aberto.

Apesar de resultados discrepantes e confusos, não se pode prescindir dessas variáveis caso se queira buscar explicações para as considerações positivas à ideia de "rouba, mas faz". A adição delas nos modelos de análise sempre gera fortes aumentos dos valores de qui-quadrado, indicando que as suas incorporações ajudam no aumento de capacidade explicativa dos testes de regressão aplicados.

A relevância explicativa das condições socioeconômicas e demográficas apresenta-se muito semelhante nos dois surveys. Neles, pode-se observar que os cidadãos brancos e com maiores rendas familiares estão associados negativamente com a aceitação da ideia de "rouba, mas faz"; já os mais jovens e os menos escolarizados encontram-se em situação oposta. Assim, pode-se afirmar que as hipóteses três, quatro e cinco são corroboradas.

No que concerne às variáveis de exposição a conteúdo midiático e "vencedores" e "perdedores" da eleição presidencial anterior, observa-se que a inserção delas no modelo gera aumento de valor de qui-quadrado em magnitude muito inferior ao acréscimo proporcionado pela inserção de variáveis avaliativas no ano de 2002. O cenário é um pouco distinto em 2006, uma vez que as incorporações de variáveis nos modelos 2 e 3 ocasionam aumentos de valores de qui-quadrado em patamares parecidos. Somente no ano de 2006 aparecem associações estatisticamente significantes de variáveis sobre exposição a conteúdo midiático com a ideia de "rouba, mas faz", indicando que os cidadãos que menos acessam notícias veiculadas pelo Jornal Nacional são os mais simpáticos à sua aceitação. A relação entre essas variáveis apresenta a mesma direção nos dados de 2002, mas sem significância estatística. Os resultados sustentam as considerações presentes na hipótese seis.

Por último, não se observa qualquer relação estatisticamente significante entre "vencedores" das eleições presidenciais anteriores às aplicações das pesquisas de opinião e aceitação do "rouba, mas faz", tampouco padrão no sentido das associações: em 2002, elas ocorrem de modo positivo e, em 2006, de modo negativo. Assim, não se tem evidências para corroborar ou refutar a hipótese sete.

Os principais achados do artigo são dois. Primeiramente, a verificação de amplo rechaço à aceitação da ideia de "rouba, mas faz". Em todos os indicadores que formam os índices em ambos os 
BONIFÁCIO, R. A afeição dos cidadãos pelos políticos mal-afamados: identificando...

anos, há forte predominância de discordância com as afirmações lenientes com a ideia do "rouba, mas faz". Em segundo lugar, há a indicação da relevância explicativa de variáveis avaliativas e de confiança em relação a atores e instituições representativas. A despeito da dificuldade de se observar alguma tendência associativa, é facilmente identificável que a incorporação dessas variáveis ajuda a elevar a capacidade explicativa do modelo de análise empírica. Talvez a solução para o problema passe por uma reformulação na inserção dessas variáveis no teste, com a utilização de índices ao invés das variáveis desmembradas, tal como ocorreu. Outra possível solução, quiçá a mais eficiente, é a realização de uma análise empírica longitudinal mais ampla, com surveys abrangendo períodos mais longos. Essa proposta esbarra, porém, na limitação dos questionários dos surveys disponíveis, que ou não comportam variáveis sobre "rouba, mas faz" (o que se deseja explicar) ou deixam de fora as variáveis sobre confiança e/ ou avaliações de instituições e atores representativos. Por fim, há de ser enfatizado o fortalecimento de argumentos tradicionais relacionados à área de Sociologia Política, de que aspectos socioeconômicos e demográficos são importantes para se entender as orientações políticas individuais. Neste artigo, há indicação de que maiores níveis de renda e instrução estão associados negativamente a aceitação do "rouba, mas faz".

\section{Referências Bibliográficas}

AIDT, T. "Economic analysis of corruption: a survey". The Economic Journal, vol. 113, n 491, 2003.

ALDÉ, A. A construção da política: democracia, cidadania e meios de comunicação de massa. Rio de Janeiro: Editora FGV, 2004. AlmeidA, A. A cabeça do brasileiro. São Paulo: Record, 2007.

ANDERSON, C.; GUILloRY, C. "Political institutions and satisfaction with democracy: a cross-national analysis of consensus and majoritarian systems". The American Political Science Review, vol. 91, n 1, 1997.

Anderson, C.; Lotempio, A. "Winning, losing and political trust in America". British Journal of Political Science, vol. 32, 2002.

CAPpella, J.; Jamieson, K. Spiral of cynicism: the press and the public good. New York: Oxford University Press, 1997.

CASTRO, M. "O comportamento eleitoral no Brasil: diagnóstico e interpretações". Teoria e Sociedade, n 1, 1997.

Costello, A.; OsBoRne, J. "Best practices in exploratory factor analysis: four recommendations for getting the most from your analysis". Practical Assessment, Research and Evaluation, vol. 10, n 7, 2005.

Cronbach, L. "Coefficient alpha and the internal structure of tests". Psychometrika, vol. 16, n 3, 1951.

Della.Porta, D. Social capital, beliefs in government and political corruption. In: PharR, S.; Putnam, R. (Eds.). Disaffected democracies. Princeton: Princeton University Press, 2000.

DiAmOND, L.; MoRLINO, L. "The quality of democracy: an overview". Journal of Democracy, vol. 15, n 3, 2004. 2005. Assessing the Quality of Democracy: Theory and Empirical Analysis. Baltimore: Johns Hopkins University Press,

DoIG, A.; Mclvor, S. "Corruption and its control in the developmental context: an analysis and selective review of the literature". Third World Quarterly, vol. 20, n 3, 1999

EASton, D. A system analysis of political life. New York: Wiley, 1965. 
FIALho, F. M. "Vicissitudes de uma análise de survey à brasileira". Resenha de ALMEIDA, A. C. A cabeça do brasileiro. Rio de Janeiro: Record, 2007. Revista Brasileira de Ciências Sociais, vol. 23, n 66, 2008.

GofFMAN, E. Frame analysis: an essay of the organization of experience. Boston: Northeastern University Press, 1986.

Huntington, S. Political order in changing societies. New Haven: Yale University Press, 1968.

. A terceira onda: a democratização no final do século XX. São Paulo: Ática, 1994.

INGLEHART, R. Culture shift in advanced societies. Princeton: Princeton University Press, 1990.

IYENGAR, S.; KINDER, D. News that matters. Chicago: University of Chicago Press, 1987.

KEY, V. Southern politics in state and nation. New York: Vintage Books, 1949.

KIM, J.; MuelLeR, C. Factor analysis: statistical methods and practical issues. Beverly Hills: Sage Publications, 1978.

KLITGAARD, R. Controlling Corruption. Los Angeles: University of California Press, 1988.

Lazarsfeld, P.; Berelson, B.; Gaudet, H. The People's Choice: how to voter makes up his mind in a presidential campaign. New York: Columbia University Press, 1948.

LeYS, C. What are the problems about corruption? In: HeIDENHEIMER, A.; Johnston, M.; LeVIne, V. (Eds.). Political corruption: a handbook. New Brunswick: Transaction, 1989.

MAURO, P. "Corruption and growth". Quarterly Journal of Economics, vol. 110, n 3, 1995.

MERTON, R. Social theory and social structures. New York: Free Press, 1957

Mesquita, N. C. "Mídia e democracia no Brasil: Jornal Nacional, Crise Política e Confiança nas Instituições". São Paulo. Tese de Doutorado em Ciência Política. FFLCH.USP, 2008.

Moısés, J. A confiança e seus efeitos sobre as instituições democráticas. In: Molsés, J. (Org.). Democracia e confiança: por que os cidadãos desconfiam das instituições públicas? São Paulo: Edusp, 2010.

; CARneIRo, G. "Democracia, desconfiança política e insatisfação com o regime: o caso do Brasil". Opinião Pública, vol. 14, n 1,2008

Democracia, desconfiança política e insatisfação com o regime: o caso do Brasil. In: Moısés, J. (Org.) Democracia e confiança: por que os cidadãos desconfiam das instituições públicas? São Paulo: Edusp, 2010.

NEWTON, K. "Mass media effects: mobilization or media malaise?" British Journal of Political Science, vol. $29, \mathrm{n}^{\circ} 4$, 1999.

NoRrIS, P. “Does television erodes social capital? A reply to Putnam”. PS: Political Science \& Politics, vol. $29, \mathrm{n}^{\circ} 3,1996$.

Institutional explanation for political support. In: NoRRIS, P. (Org.). Critical citizens: global support for democratic government. New York: Oxford University Press, 1999. 2000

A Virtuous Circle: Political Communications in Post-Industrial Democracies. Cambridge: Cambridge University Press

NYE, J. "Corruption and political development: a cost-benefit analysis". American Political Science Review, vol. 61, $\mathrm{n}^{\circ} 2$, 1967.

Offe, C. How can we trust our fellow citizens? In: WarRen, M. (Org.). Democracy and trust. Cambridge: Cambridge University Press, 1999

PATTERSON, T. Out of order. New York: Vintage Books, 1993.

Putnam, R. "Tuning in, Tuning out: the strange disappearance of social capital in America". PS: Political Science \& Politics, vol. 27, $n^{\circ} 4,1995$.

Bowling alone: the collapse and revival of american community. New York: Simon and Schuster, 2001. 
BONIFÁCIO, R. A afeição dos cidadãos pelos políticos mal-afamados: identificando...

RenNó, L. "Escândalos e voto: as eleições presidenciais de 2006”. Opinião Pública, vol.13, n 2, 2007.

RoBINSON, M. "Public affairs television and the growth of political malaise: the case of 'The selling of pentagon'". American Political Science Review, nº 70, 1976.

Rose-ACKERmAn, S. Corruption and government: causes, consequences and reform. Cambridge: Cambridge University Press, 1999.

Schlegel, R. "Mídia, Confiança Política e Mobilização". São Paulo. Dissertação de Mestrado em Ciência Política. FFLCH. USP, 2005.

SELIGSON, M. "The impact of corruption on regime legitimacy: a comparative study of four Latin American countries". Journal of Politics, vol. 64, n², 2002.

SHLEIFER; A.; VISHNY, R. "Corruption". The Quarterly Journal of Economics, vol. 108, n 3, 1993.

"Stock market driven acquisitions". Journal of Financial Economics, vol. 70, n 3, 2003.

TULLOCK, G. "The welfare costs of tariffs, monopolies, and theft". Western Economic Journal, n 5, 1967.

TVERSKY, A.; KAHNEMAN, D. "Advances in prospect theory: cumulative representation of uncertainty". Journal of Risk and Uncertainty, vol. 5, 1992.

WATERBURY, J. "Corruption, political stability and development: comparative evidence from Egypt and Morocco". Government and Opposition, vol. 11, n 4, 1976.

WINTERS, M.; WeITZ-SHAPIRO, R. “'Rouba, mas faz' or not? Exploring voter attitudes toward corruption in Brazil”. Trabalho apresentado no Annual Meeting of the American Political Science Association, Washington D.C, 2010.

Wraith, R.; SIMPKINS, E. Corruption in Developing Countries. Londres: Allen and Unwin, 1963.

Robert Bonifácio - robertbonifacio@hotmail.com

Submetido à publicação em novembro de 2011.

Aprovado para publicação em janeiro de 2012. 